\title{
Avaliação computacional da compactação da cromatina e de características morfométricas da cabeça de espermatozoides de coelho (Oryctolagus cuniculus)
}

\author{
[Computational evaluation of chromatin condensation and morphometric characteristics of rabbit \\ (Oryctolagus cuniculus) sperm head] \\ C.Y. Kanayama ${ }^{1}$, M.E. Beletti $i^{2 *}$ \\ ${ }^{1}$ Instituto de Estudos Avançados em Veterinária “José Caetano Borges” - UNIUBE - Uberaba, MG \\ ${ }^{2}$ Instituto de Ciências Biomédicas - UFU \\ Av. Pará, 1720 \\ 38400-902 - Uberlândia, MG
}

\begin{abstract}
RESUMO
Investigou-se a correlação entre a morfometria da cabeça e a intensidade da condensação e heterogeneidade da cromatina em espermatozoides de coelho (Oryctolagus cuniculus). Para tal, utilizaram-se 35 esfregaços de sêmen de coelhos da raça Nova Zelândia, corados com azul de toluidina e avaliados por análise de imagem computacional. As imagens foram obtidas digitalmente em tons de cinza e avaliadas por algoritmos desenvolvidos em ambiente de programação Scilab. As mensurações obtidas da cabeça dos espermatozoides foram área, perímetro, comprimento, largura, relação comprimento largura, elipsidade, fator de forma, descritores Fourier e simetria lateral e anteroposterior. Também foram avaliadas a intensidade da compactação e a heterogeneidade da cromatina espermática. Os espermatozoides de coelho apresentaram compactação e heterogeneidade cromatínica mais intensas do que os de touro e observou-se correlação significativa entre características morfométricas da cabeça e compactação e heterogeneidade cromatínica. Conclui-se que a cromatina é importante para a constituição morfológica da cabeça de espermatozoides de coelho e que a cromatina espermática de coelho é naturalmente mais heterogênea e menos compactada que a de touro.
\end{abstract}

Palavras-chave: coelho, análise de imagem, morfometria espermática, alterações de cromatina

\begin{abstract}
The correlation between the head morphometry and the intensity of condensation and heterogeneity of sperm chromatin were investigated in rabbit (Oryctolagus cuniculus). To this, 35 semen smears from New Zealand rabbits were stained with toluidine blue and evaluated by computer image analysis. The images were obtained in digital grayscale and analyzed by algorithms developed in the Scilab programming environment. The measurements obtained from the sperm heads were area, perimeter, length, width, length:width ratio, ellipticity, shape factor, lateral and anterior-posterior symmetries, and Fourier descriptors. The intensity and heterogeneity of the compaction of sperm chromatin was also evaluated. The rabbit spermatozoa showed chromatin heterogeneity and condensation more intense than the bull spermatozoa, and it was observed correlation between morphometric characteristics of the head and chromatin compaction and heterogeneity. The results suggest that chromatin is important for the morphological constitution of the head morphology spermatozoa head, as well as, rabbit sperm chromatin is inherently more heterogeneous and less condensed than the bull sperm chromatin.
\end{abstract}

Keywords: image analysis, sperm morphometry, toluidine blue, chromatin alterations

Recebido em 4 de julho de 2010

Aceito em 10 de fevereiro de 2011

*Autor para correspondência (corresponding author)

E-mail:mebeletti@ufu.br 


\section{INTRODUÇÃO}

Os espermatozoides de mamíferos contêm a cromatina em seu maior grau de compactação. O DNA é compactado pela substituição das proteínas histônicas, que participam da arquitetura molecular das fibras cromatínicas de células somáticas, por protaminas, que são proteínas ricas em arginina, resíduos de lisina e cisteína e pontos de ligações fosforiladas (Balhorn, 2007). Essa substituição das proteínas ocorre durante a espermatogênese e no trânsito epididimário. O DNA compactado tem forma toroidal semelhante a doughnut estabilizados por pontes dissulfeto entre as protaminas (Shaman et al., 2007). As protaminas são importantes na condensação do material genético, tornando o núcleo mais compacto e hidrodinâmico. Além disso, devido à extrema condensação, o DNA fica protegido contra a ação de agentes mutagênicos, radicais livres e nucleases (Oliva, 2006).

Alterações na compactação da cromatina espermática levam a problemas de fertilidade no macho. Gledhill (1966) foi o primeiro a identificar espermatozoides com cromatina malcompactada em touros subférteis, utilizando reação de Feulgen. Outro método empregado para avaliação da cromatina foi desenvolvido por Mello (1982), o qual emprega o azul de toluidina, um corante catiônico que apresenta metacromasia. Assim como os métodos normalmente utilizados no espermograma de rotina, estes métodos utilizam avaliação visual e, portanto, possuem certo grau de subjetividade. Já o sperm chromatin structure assay (SCSA), que utiliza citometria de fluxo, é um método de avaliação da cromatina com menor subjetividade, no entanto de alto custo (Evenson et al., 1980; Silva et al., 2009). Na tentativa de tornar as avaliações espermáticas mais objetivas e de custo acessível a veterinários de campo, têm-se desenvolvido métodos de avaliação computacional da morfometria e da compactação cromatínica espermática (Beletti et al., 2005a; Silva et al., 2008; Rodrigues et al., 2009).

O método proposto por Beletti et al. (2005a), além de ser objetivo e de baixo custo, permite a avaliação concomitante da cromatina e da morfometria da cabeça espermática, o que não é possível nem mesmo com o SCSA, considerado o "método ouro" para avaliação da cromatina.
Essa propriedade permite verificar se realmente existe uma correlação entre a forma da cabeça do espermatozoide e a compactação da cromatina (Boe-Hansen et al., 2008; Silva et al., 2008; Rodrigues et al., 2009). Tal método até hoje só foi utilizado para espermatozoides de touro (Beletti et al., 2005a; Silva et al., 2008) e de galo (Rodrigues et al., 2009), assim é necessária sua validação para outras espécies.

O objetivo deste trabalho foi avaliar a correlação entre condensação da cromatina e morfometria da cabeça de espermatozoides de coelhos, utilizando análise computacional de imagens digitais de esfregaços de sêmen corados com azul de toluidina.

\section{MATERIAL E MÉTODOS}

Foram utilizadas 35 amostras de sêmen de diferentes coelhos adultos da raça Nova Zelândia brancos, coletadas por meio de vagina artificial. Depois da coleta, foram realizados esfregaços, que foram fixados com etanol-acético (3:1, V/V) por um minuto e posterior imersão em etanol a $70 \%$ por três minutos. Após esta etapa, foi realizada a hidrólise ácida em $\mathrm{HCl} 4 \mathrm{~N}$ a $25^{\circ} \mathrm{C}$ por 15 minutos, seguida de coloração com azul de toluidina 0,025\% em tampão McIlvaine (citratofosfato sódio) e pH 4 (Beletti e Mello, 2004). Foram obtidas 100 imagens digitais de cada esfregaço, por meio de microscópio óptico (Zeiss Axiolab), em objetiva de 100x (imersão), acoplado a uma câmera digital (Nikon 300Y) e conectado a um microcomputador por meio de placa digitalizadora (Pcmcia Type II TV Tuner Card). As imagens foram capturadas digitalmente em tons de cinza.

Utilizou-se um programa de processamento de imagens (Paint Shop Pro 8) para segmentar interativamente 100 cabeças de espermatozoides de cada esfregaço, totalizando 3500 cabeças. Todas as cabeças foram avaliadas por algoritmos desenvolvidos em ambiente de programação matemática SCILAB (Beletti e Costa, 2003; Beletti et al., 2004; Beletti et al., 2005a;b). Inicialmente o algoritmo avaliou os pixels de cada cabeça em um esfregaço e selecionou as 20 cabeças com valores de pixel mais homogêneos (menores desvios-padrão), e dentre essas, o programa selecionou as seis cabeças com maior média dos valores de pixel, ou seja, as menos coradas. Essas cabeças teoricamente são as de 
cromatina mais compactada, e a média dos valores de pixel que as constituem passa a ser considerada como o valor padrão do esfregaço. Posteriormente, foi determinada a diferença entre o valor padrão do esfregaço da qual a cabeça foi segmentada e a média dos valores de pixel de cada cabeça analisada. A diferença encontrada foi transformada em porcentagem (Dif\%) da média dos valores de pixel de cada cabeça. Também foi calculado o coeficiente de variação (CV) da intensidade de tons de cinza de cada cabeça, o qual representa quantitativamente a heterogeneidade da compactação da cromatina na cabeça (Beletti et al., 2005a).

A área (A), o perímetro (P), a largura (L), o comprimento $(\mathrm{C})$, a relação comprimento largura $(\mathrm{L} / \mathrm{C})$, a elipsidade (e) e o fator forma $(\mathrm{FF})$ de todas as cabeças foram determinados pelo uso dos algoritmos em SCILAB (Beletti e Costa, 2003). Descritores Fourier com amplitude de 0 a 2 (F0, F1, F2) foram determinados para caracterização e análise da forma (Beletti e Costa, 2003; Beletti et al., 2005a;b). A simetria da cabeça espermática também foi avaliada, sendo calculada a simetria lateral (SL) e a simetria anteroposterior (SAP) (Beletti e Costa, 2003; Beletti et al., 2005a;b).

Os coeficientes de correlação (correlação de Pearson) entre as características morfométricas da cabeça do espermatozoide e as características de anormalidade da compactação da cromatina
(Dif\% e CV) foram calculados utilizando-se o software S-plus 2000. Valores de $\mathrm{P}<0,05$ indicam significância estatística.

\section{RESULTADOS E DISCUSSÃO}

As médias e os desvios-padrão de todas as características avaliadas são apresentados na Tab. 1, e os coeficientes de correlação entre as variáveis que caracterizam a compactação de cromatina e as características morfométricas da cabeça do espermatozoide na Tab. 2.

Tabela 1. Características morfométricas, avaliadas por análise computacional, da cabeça dos espermatozoides de coelho (média \pm desviopadrão)

\begin{tabular}{lc}
\hline Variável & Média \\
\hline Área $\left(\mu \mathrm{m}^{2}\right)$ & $33,3 \pm 3,9$ \\
Perímetro $(\mu \mathrm{m})$ & $20,1 \pm 1,4$ \\
Largura $(\mu \mathrm{m})$ & $4,0 \pm 0,3$ \\
Comprimento $(\mu \mathrm{m})$ & $7,5 \pm 0,3$ \\
Largura/Comprimento & $0,54 \pm 0,04$ \\
Elipsidade & $0,30 \pm 0,03$ \\
Fator de forma & $0,92 \pm 0,03$ \\
Fourier 0 & $1995,6 \pm 298,5$ \\
Fourier 1 & $138,2 \pm 76,2$ \\
Fourier 2 & $193,0 \pm 92,4$ \\
Simetria lateral & $0,96 \pm 0,02$ \\
Simetria anteroposterior & $0,95 \pm 0,02$ \\
Heterogeneidade da cromatina (\%) & $10,3 \pm 3,6$ \\
Descompactação da cromatina & $5,3 \pm 4,19$ \\
(Dif\%)(\%) & \\
\hline
\end{tabular}

Tabela 2. Coeficiente de correlação entre as variáveis relacionadas à compactação da cromatina e as variáveis morfométricas da cabeça do espermatozoide

\begin{tabular}{lcc} 
& $\begin{array}{c}\text { Coeficiente de } \\
\text { correlação } \\
(\%)\end{array}$ & $\begin{array}{c}\text { Diferença } \\
\text { valor de pixel } \\
(\%)\end{array}$ \\
\hline Área $\left(\mu \mathrm{m}^{2}\right)$ & $-0,34^{*}$ & $-0.18^{*}$ \\
Perímetro $(\mu \mathrm{m})$ & $-0.26^{*}$ & $-0.13^{*}$ \\
Largura $(\mu \mathrm{m})$ & $-0.31^{*}$ & $-0.17^{*}$ \\
Comprimento $(\mu \mathrm{m})$ & $-0.20^{*}$ & $-0.06^{*}$ \\
Largura/Comprimento & $-0.18^{*}$ & $-0.15^{*}$ \\
Elipsidade & $0.19^{*}$ & $0.15^{*}$ \\
Fator de forma & $0.04^{*}$ & -0.01 \\
Fourier 0 & $-0.07^{*}$ & -0.01 \\
Fourier 1 & $0.19^{*}$ & $0.12^{*}$ \\
Fourier 2 & $-0.07^{*}$ & $-0.05^{*}$ \\
Simetria lateral & $-0.07^{*}$ & $-0.03^{*}$ \\
Simetria anteroposterior & $-0.32^{*}$ & $-0.17^{*}$ \\
Heterogeneidade da cromatina $(\%)$ & $1.00^{*}$ & $0.61^{*}$ \\
Descompactação da cromatina $(\%)$ & $0.61^{*}$ & $1.00^{*}$ \\
\hline
\end{tabular}


Os valores médios para as características morfométricas da cabeça de espermatozoides de coelho mostraram-se semelhantes aos encontrados por Beletti et al. (2005b) para espermatozoides de touros. Entretanto, são menores quando comparados com os de suínos (Saravia et al., 2007) e maiores que os de garanhões (Gravance et al., 1996). Em relação às características relacionadas à compactação de cromatina ( $\mathrm{CV}$ e Dif\%), os valores médios encontrados foram mais elevados que os encontrados por Beletti et al. (2005a), para espermatozoides considerados normais, e mesmo em relação aos considerados anormais encontrados em touros férteis. Os animais utilizados no presente trabalho não foram selecionados; desse modo, provavelmente foram usados animais férteis e subférteis. Assim, os valores médios de $\mathrm{CV}$ e Dif\% sofreram influência do grande número de espermatozoides anômalos encontrados nos animais subférteis. Mas, mesmo quando comparados com espermatozoides de touros considerados anômalos (Beletti et al., 2005a), os valores obtidos neste trabalho foram mais altos. Possivelmente, porque os espermatozoides de coelho possuem a cromatina mais heterogênea na extensão de sua cabeça, aumentando o coeficiente de variação dos valores dos pixels (CV) que compõem a imagem, ou seja, os pixels tinham maior variação de cor na extensão da cabeça, diferentemente dos espermatozoides de touro. É importante salientar que o $\mathrm{CV}$ não é uma medida estatística dos resultados obtidos, mas sim uma característica morfométrica que representa de forma quantitativa a heterogeneidade da compactação da cromatina dentro de uma cabeça (Beletti et al., 2005a). Também provavelmente os espermatozoides de coelho possuem maior variação de compactação na cromatina entre espermatozoides normais e anômalos, aumentando a média geral da Dif\%. Portanto, não se devem utilizar os mesmos valores de Dif\% e CV encontrados em touros para se identificar alterações da fertilidade em coelhos.

Todos os coeficientes de correlação entre as características morfométricas e as relacionadas com a compactação de cromatina foram significativos, exceto entre Dif\% e FF e F0, diferindo do obtido por Beletti et al. (2005a). Isso provavelmente ocorreu porque, no presente trabalho, avaliaram-se 3500 cabeças de espermatozoides e, na pesquisa de Beletti et al. (2005a), somente 750. Independentemente do número de cabeças avaliadas, percebe-se que as variáveis morfométricas de tamanho (A, P, L e C) são geralmente correlacionadas negativamente com as de compactação de cromatina (CV e Dif\%), ou seja, as cabeças menos compactadas e com cromatina mais heterogênea tendem a possuir cabeças com área menor. Contudo, era de se esperar que espermatozoides com menor compactação cromatínica possuíssem cabeças com maior volume. Uma possível explicação para essa contradição é que nesses trabalhos a maior parte da cabeça com alterações possuía cromatina levemente mais frouxa e isso poderia apenas torná-la um pouco mais esférica, diminuindo a área e aumentando a altura e, consequentemente, o volume da cabeça. É importante salientar que a cabeça dos espermatozoides de touro e de coelho são achatadas e que as avaliações morfométricas utilizadas nesses trabalhos são bidimensionais, não existindo necessariamente relação entre a área avaliada e o volume da cabeça do espermatozoide.

Os coeficientes de correlação entre $\mathrm{L} / \mathrm{C}$ e as variáveis relacionadas à compactação de cromatina foram negativos tanto para CV quanto para Dif\%, ao contrário do observado em relação à elipsidade. Ambos os casos demonstram que quanto mais heterogênea e menos compactada a cromatina espermática mais longa tende a ser a cabeça do espermatozoide. Já o fator de forma está correlacionado positivamente para a heterogeneidade, e negativamente, mas não de forma significativa, para a descompactação da cromatina. Os valores dessas correlações em espermatozoide de touros variam muito de amostra para amostra de sêmen (Beletti et al., 2005a). Ferrari et al. (1998) encontraram espermatozoides estreitos na base e com cabeças piriformes em alterações cromatínicas. Entretanto, outras correlações entre forma e alteração cromatínicas não foram observadas.

Ostermeier et al. (2001) e Sailer et al. (1996) descreveram que há correlação significativa entre anomalia na cromatina e alterações na morfologia da cabeça do espermatozoide, ao usarem a técnica SCSA para analisar a cromatina. Contudo, essa metodologia não avalia simultaneamente a compactação da cromatina e a morfometria em um mesmo espermatozoide, 
portanto a correlação foi feita com as variáveis obtidas em cada amostra. A avaliação computacional descrita no presente trabalho permitiu correlacionar diretamente compactação da cromatina e morfometria em um mesmo espermatozoide, transformando cada espermatozoide em uma amostra.

Em espermatozoides de touros, as harmônicas de Fourier zero e dois geralmente apresentam correlação negativa, e a um positiva em relação a CV e Dif\% (Beletti et al., 2005a). As correlações obtidas para espermatozoides de coelho foram muito semelhantes.

A simetria lateral apresenta correlação negativa significativa em relação à descompactação de cromatina, demonstrando que espermatozoides com cromatina mais frouxa tendem a ser menos simétricos lateralmente. Em relação à simetria antero-posterior, há correlação negativa tanto para CV como para Dif\%, ou seja, espermatozoide com alta simetria anteroposterior, geralmente, apresenta cromatina mais descompactada e heterogênea, semelhante ao encontrado em touros (Beletti et al., 2005a).

O fato de ocorrer correlação significativa entre a descompactação e a heterogeneidade da cromatina e a maioria das características morfométricas da cabeça do espermatozoide demonstra que a estrutura cromatínica é importante na definição da forma da cabeça.

\section{CONCLUSÕES}

O método de análise computacional de imagens de esfregaços corados com azul de toluidina mostrou que a cromatina espermática de coelho é naturalmente mais heterogênea e menos compactada que a de touro, desse modo não devem ser utilizados os mesmos valores para as duas espécies para se determinar alterações na fertilidade. Independentemente desses valores, pode-se afirmar que há correlação entre as características morfométricas da cabeça e a descompactação e a heterogeneidade da cromatina de espermatozoides de coelho, assim como de touro, demonstrando que a cromatina é importante para definir a morfologia da cabeça.

\section{AGRADECIMENTOS}

Os autores agradecem à FAPEMIG e ao CNPq, pelo suporte financeiro.

\section{REFERÊNCIAS BIBLIOGRÁFICAS}

BALHORN, R. The protamine family of sperm nuclear proteins. Genome Biol., v.8, p.227-235, 2007.

BELETTI, M.E.; COSTA, L.F. A systematic approach to multi-species sperm morphometrical characterization. Anal. Quant. Cytol. Histol., v.25, p.97-107, 2003.

BELETTI, M.E.; COSTA, L.F.; GUARDIEIRO, M.M. Morphometric features and chromatin condensation abnormalities evaluated by toluidine blue staining in bull spermatozoa. Braz. J. Morphol. Sci., v.22, p.85-90, 2005a.

BELETTI, M.E.; COSTA, L.F.; VIANA, M.P. A comparison of morphometric characteristics of sperm from fertile Bos taurus and Bos indicus bulls in Brazil. Anim. Reprod. Sci., v.85, p.105116, $2005 b$.

BELETTI, M. E.; COSTA, L. F.; VIANA, M. P. A computational approach to the characterization of bovine sperm chromatin alterations. Biotech. Histochem., v.79, p.17-23, 2004.

BELETTI, M.E.; MELLO, M.L.S. Comparison between the toluidina blue stain and the Feulgen reaction for evaluation of rabbit sperm chromatin condensation and their relationship with sperm morphology. Theriogenology, v.62, p.398-402, 2004

BOE-HANSEN, P.; CHRISTENSEN, D.; VIBJERG, M. et al. Sperm chromatin structure integrity in liquid stored boar semen and its relationships with field fertility. Theriogenology, v.69, p.728-736, 2008.

EVENSON, D.P.; DARZYNKIEWICZ, Z.; MELAMED, M.R. Relation of mammalian sperm chromatin heterogeneity to fertility. Science, v.210, p.1131-1133, 1980.

FERRARI, M.R.; SPIRITO, S.E.; GIULIANO, S.M. et al. Chromatin cytophotometric analysis of normal bovine spermatozoa. Andrologia, v.30, p.85-89, 1998. 
GLEDHILL, B.L. Studies on the DNA content, dry mass and optical even of morphologically normal and abnormal bull spermatozoa heads. Acta Vet. Scand., v.7, p.1-20, 1966.

GRAVANCE, B.P.; LIU, I.K.M.; DAVIS, R.O. et al. Quantification of normal head morphology of stallion spermatozoa. J. Reprod. Fertil., v.108, p.41-46, 1996.

MELLO, M.L. Induced metachromasia in bull spermatozoa. Histochemistry, v.74, p.387-392, 1982.

OLIVA, R. Protamines and male infertility. Hum. Reprod. Update, v.13, p.417-435, 2006.

OSTERMEIER, G.C.; SARGEANT, G.A.; YANDELL B.S. et al. Relationship of bull fertility to sperm nuclear shape. J. Androl., v.22, p.595-603, 2001.

RODRIGUES, A.C.N.; ROCHA, J.V.; BELETTI, M.E. Análise computacional da compactação da cromatina de espermatozoides de galo. Arq. Bras. Med. Vet. Zootec., v.61, p.1302-1307, 2009

SAILER, B.L.; JOST, L.K; EVENSON, D.P. Bull sperm morphometry related to abnormal chromatin structure and fertility. Cytometry, v.24, p.167-173, 1996.
SARAVIA, F.; NÚÑEZ-MARTÍNEZ, I.; MORÁN, J.M. et al. Differences in boar sperm head shape and dimensions recorded by computer-assisted sperm morphometry are not related to chromatin integrity. Theriogenology, v.68, p.196-203, 2007.

SILVA, R.T.; MENDES JÚNIOR, J.O.B.; BELETTI, M.E. Compactação da cromatina e morfometria da cabeça de espermatozoides na produção de embriões in vitro utilizando touros zebuínos. Acta Sci. Anim. Sci., v.30, p.473-478, 2008.

SILVA, K.M.G.; MORAES, T.A.P.; SILVA, E.C.B. et al. Efeito da adição de trolox e pentoxifilina na motilidade, integridade do acrossoma e do DNA de espermatozoides equinos após descongelação. Arq. Bras. Med. Vet. Zootec., v.61, p.42-49, 2009.

SHAMAN, J.A.; YAMAUCHI, Y.; WARD, W.S. Function of the sperm nuclear matrix. Arch. Androl., v.53, p.135-140, 2007. 